\title{
ESPIRITUALIDAD SACERDOTAL
}

Mons. Dr. EnRIQue Glennie Graue ${ }^{1}$

ÍNDICE

INTRODUCCIÓN

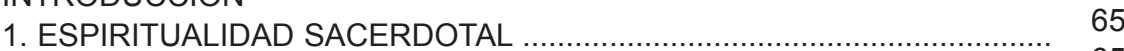

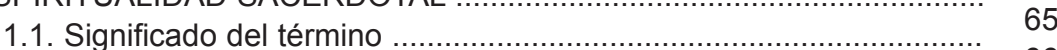

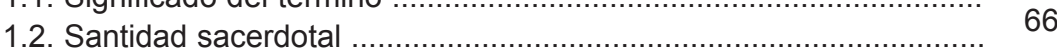

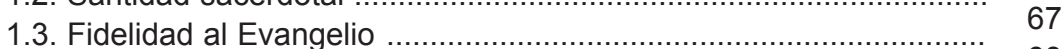

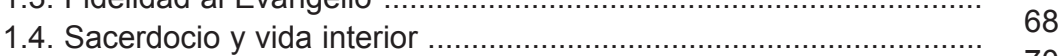

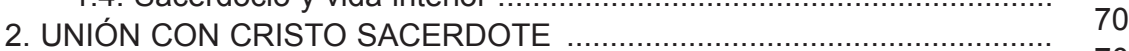

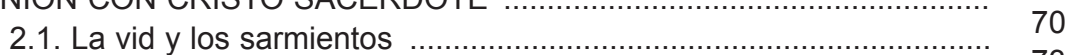

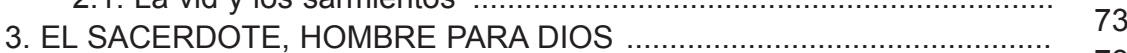

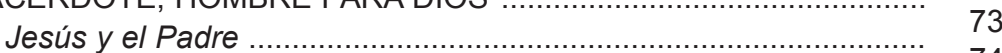

El silencio

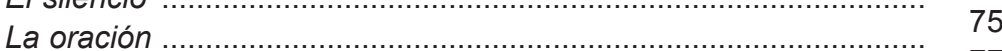

4. SU PERTENENCIA A LA IGLESIA …

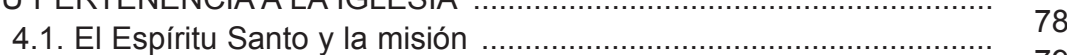

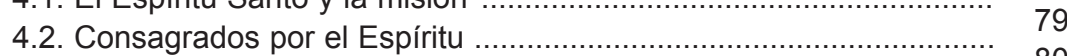

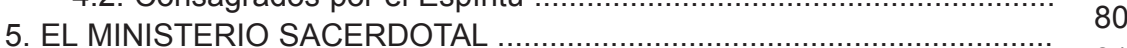

5.1. El Buen Pastor $\quad 81$

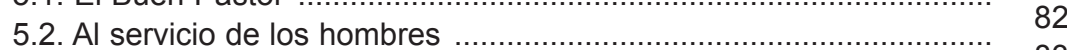

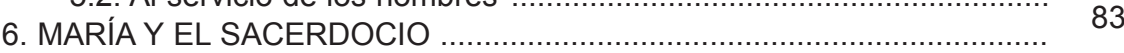

Excursus sobre espiritualidad sacerdotal, según la exhortación Pastores Dabo Vobis, de Juan Pablo II

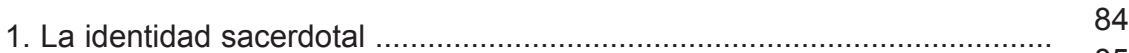

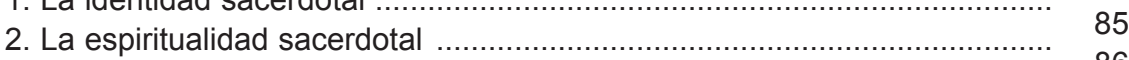

2.1. La espiritualidad del Esposo ............................................... 86

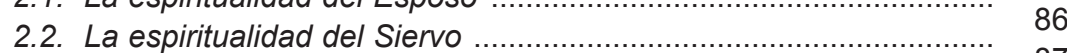

2.3. La espiritualidad del Hermano .................................................. 87

2.4. La vida espiritual, una respuesta ........................................... 88

1 Nació en la ciudad de México en 1947 y fue ordenado en su diócesis en 1972. Doctor en teología espiritual por la la universidad Gregoriana de Roma y master en Matrimonio y Familia por la universidad de Navarra ha publicado diversos libros sobre la espiritualidad sacerdotal (1982) En la actualidad es Vicario General de Pastoral. 
La Espiritualidad no es una moda. Es una actitud fundamental ante la Verdad y supone un estilo de vida específico y comprometido por parte de cada creyente. De manera especial, el sacerdote, religioso o diocesano, debe asumir consciente y responsablemente su espiritualidad como expresión de su propia identidad en la Iglesia y en el mundo.

Este Año Sacerdotal, decretado por su Santidad Benedicto XVI, nos brinda la oportunidad de reflexionar personal o comunitariamente en la verdad de nosotros mismos como sacerdotes para enriquecer más nuestra experiencia de Dios y nuestro ministerio al servicio de los demás.

\section{INTRODUCCIÓN}

Hablar de la espiritualidad del sacerdote supone entrar en un mundo de reflexiones y consideraciones que sería imposible abarcar en su totalidad y extensión. Hay elementos que forman parte de la espiritualidad propiamente sacerdotal, pero que también de alguna manera constituyen la espiritualidad cristiana. Con frecuencia también, se estudia la espiritualidad sacerdotal en forma negativa, es decir, comparando con la espiritualidad de los religiosos y de los laicos y manifestando lo que no es característicamente sacerdotal de estas formas de espiritualidad.

Cuando nos referimos a la espiritualidad del sacerdote, suponemos naturalmente que el concepto de santidad aplicado al sacerdote es válido también para todos los cristianos; que la santidad es para todos:

En la Iglesia, todos, lo mismo quienes pertenecen a la Jerarquía que los apacentados por ella, están llamados a la santidad, según aquello del Apóstol: 'Porque ésta es la voluntad de Dios, vuestra santificación' (1 Tes. 4,3; cfr. Ef. 1,4). Esta santidad de la Iglesia se manifiesta y sin cesar debe manifestarse en los frutos de gracia que el Espíritu produce en los fieles. Se expresa multiformemente en cada uno de los que, con edificación de los demás, se acercan a la perfección de la caridad en su propio género de vida... (LG. 39)

Para el sacerdote se tratará de la aplicación integral del Evangelio a su vida sacerdotal. No se trata de hacer del sacerdote un supercristiano o un cristiano diferente; por tanto, cuando se habla de espiritualidad sacerdotal, no se puede aislar ésta de la espiritualidad cristiana y en concreto, del Misterio Pascual.

Son ya casi dos mil años que el sacerdocio existe en la Iglesia. A partir del método histórico se podría estudiar cuáles han sido las principales virtudes cristianas sacerdotales a lo largo de la historia de la Iglesia. Este método 
positivo-histórico vale, suponiendo que el sacerdocio se haya vivido siempre en conformidad con su propia naturaleza.

Otra forma de proceder también en este estudio sería la forma descriptivofenomenológica, dejando a un lado toda otra reflexión. Estaría también el método teológico-especulativo, partiendo de la noción misma de espiritualidad. Es difícil hablar de espiritualidad sacerdotal por el inmenso pluralismo que existe en este campo; aún a riesgo de generalizar demasiado o al contrario, de particularizar demasiado, trataré de exponer algunos, no todos, de los elementos que se sitúan como más característicos de la espiritualidad sacerdotal, dejando, a través de la lectura de la bibliografía presentada y de la reflexión personal o grupal, las consideraciones más concretas y pertinentes de acuerdo con las exigencias particulares.

Hoy, a partir del Concilio Vaticano II, tenemos ya una serie de tomas de posición respecto a la espiritualidad del sacerdote. Antes del Concilio se veía la espiritualidad sacerdotal en contraposición con la actividad y la vida apostólica; el Concilio hace la unidad entre ambas.

Para conseguir sus fines pastorales de renovación interna de la
Iglesia, de difusión del Evangelio por el mundo entero así como de
diálogo con el mundo actual, este sacrosanto Concilio exhorta vehe-
mentemente a todos los sacerdotes a que, empleando los medios
recomendados por la lglesia, se esfuercen por alcanzar una santi-
dad cada vez mayor, para convertirse, día a día, en más aptos
instrumentos en servicio de todo el Pueblo de Dios (PO 12).

Afirma, además, el Concilio que los sacerdotes conseguirán la santidad en el apostolado, siempre y cuando se haga en el Espíritu de Cristo: Los presbíteros conseguirán de manera propia la santidad ejerciendo sincera e incansablemente sus ministerios en el Espíritu de Cristo (PO, 13).

Característica también del estilo espiritual de vida del sacerdote es su comunión con Cristo Sacerdote y con el Obispo: Por el Sacramento del Orden se configuran los Presbíteros con Cristo Sacerdote, como ministros de la Cabeza, para construir y edificar todo su cuerpo, que es la Iglesia, como cooperadores del Orden Episcopal (PO, 12).

Ha sido frecuente ver el apostolado separado de la propia santificación. Cuando hablamos de santificación, no se puede entender de santificación automática, como si el simple hecho del apostolado diera ya de por sí la santidad. El sacerdote debe preocuparse por santificarse, contando, desde luego, con la gracia de la Ordenación.

La fuente y raíz de la vida espiritual para el sacerdote es la Eucaristía, ya que Cristo, Sumo y Eterno Sacerdote, realiza siempre su sacrificio en la Iglesia; es por eso que el Sacerdote debe actuar siempre en unión con Cristo y con el mismo método de Jesucristo. Cristo tiene una relación interpersonal con su 
Padre; esta relación es importante y necesaria para el sacerdote, aunque la forma concreta de esta relación pueda cambiar según el tiempo; esta relación interpersonal con el Padre, que lo constituye hombre para Dios, le potenciará una actitud apostólica ministerial de acuerdo con el Espíritu de Cristo, y en íntima y profunda relación o comunión con la Iglesia. La espiritualidad sacerdotal es absolutamente eclesial.

Una exigencia también fundamental en la vida espiritual del sacerdote es la comunión con Cristo sacerdote a través de su misterio pascual, de muerte y resurrección. Por eso el sacerdote es, sobre todo, testigo de la Pascua:

El Presbitero es un hombre de Dios. Sólo puede ser profeta en la medida en que haya hecho la experiencia del Dios vivo. Sólo esta experiencia lo hará portador de una Palabra poderosa para transformar la vida personal y social de los hombres de acuerdo con el Designio del Padre" (III Conf. Gral. del Episcopado Latinoamericano, Puebla, 1979, \# 693).

La experiencia de Dios, como experiencia de la Pascua, lo capacitará para cumplir su ministerio de hombre de Dios para los hombres.

Algunos de estos puntos que aquí he enumerado brevemente trataré de irlos presentando un poco más ampliamente, sin la pretensión de abarcar la totalidad de los temas y remitiéndome siempre a la bibliografía presentada.

El evangelista san Juan nos presenta a Jesucristo como verdadero sacerdote, la máxima expresión y manifestación del Padre que nos ama: en El llega el amor del Padre hasta lo último: Tanto amó Dios al mundo que le envió a su Hijo Unigénito $(\mathrm{JN} 3,16)$.

La teología de Juan nos invita a la experiencia que él mismo ha vivido: Hemos visto, Hemos oído, Hemos tocado, pues la vida se manifestó (Cfr. 1Jn 1,1-2). Vivir el sacerdocio, sea como sacerdote ministerial, o bien, acompañar en forma vital y profunda al sacerdote, habrá de ser una invitación que pueda surgir de estas sencillas y breves reflexiones: vivir la misteriosa aventura del sacerdocio.

Teniendo en cuenta la aportación que el evangelista san Juan nos puede ofrecer, partiremos, metodológicamente hablando, de una breve consideración de su evangelio; esto, al mismo tiempo que nos dará la oportunidad de una visión amplia, nos situará en una posibilidad de experiencia abierta a cada uno. Después, teniendo en cuenta el magisterio de la Iglesia, especialmente los últimos documentos sobre el sacerdocio, trataré de ofrecer algunos puntos de reflexión. Una aclaración pertinente es que no se abordará el tema de la teología del sacerdocio como tal, sino que el enfoque será precisamente la espiritualidad sacerdotal.

La idea conclusiva sobre la espiritualidad del Sacerdote sería que la relación con Dios hace del sacerdote un hombre de oración; la relación con los hombres, lo hace hombre de acción; la relación con Cristo. lo hace hombre de 


\section{Espiritualidad sacerdotal}

ascesis y la relación con la Iglesia lo hace hombre del compromiso apostólico. Su relación personal con Cristo, sobre todo, le hará irse configurando con aquél que fue el hombre para los hombres, porque era el hombre para Dios.

\section{ESPIRITUALIDAD SACERDOTAL}

\subsection{Significado del término}

La primera pregunta que surge espontánea al considerar un título así es si se puede trazar, según los elementos de que podemos disponer, una línea o una fisonomía espiritual que sea propia del sacerdote como tal y por la cual él se distinga de los otros fieles.

A esto se puede ciertamente dar una respuesta positiva, pero será necesario siempre determinar el significado del término espiritualidad.

Podemos entenderla como doctrina o teología de la vida espiritual, que el hombre debe seguir para llegar a la salvación; tomada así, en el cristianismo hay una sola espiritualidad, sustancialmente igual para cualquier persona o grupo.

Podemos hablar también de distintos medios, formas, estados, etc. de vivir una determinada espiritualidad. Cabe notar que en todos estos casos el término espiritualidad puede siempre entenderse como conjunto de principios doctrinales.

Cuando hablamos de espiritualidad sacerdotal, no debemos entenderla en el sentido de principios de vida espiritual diversos de los que regulan la espiritualidad cristiana; es decir, se trata de un justo sistema de medios para vivir integralmente el sacerdocio, en cuanto que éste es participación del Sacerdocio único de Cristo.

Por otro lado, al hablar de espiritualidad hemos de entender no solamente un conjunto de principios teóricos, sino especialmente una reflexión sobre la vida en su forma más elemental de experiencia de la vida comunicada por Dios que se convierte en el hombre en un determinado modo de vida (Flp. $3,17-20)$ y que se caracteriza por su motivación fundamental que es el amor de Dios en cuanto perfección de la caridad y de esta manera es principio de una actividad personal en la línea de la salvación. El Concilio Vaticano II expresa con claridad el concepto general de santidad y espiritualidad para todos en L.G, 40; más adelante, en el No. 41, se expresa así, a propósito de los sacerdotes:

Una misma es la santidad que cultivan, en los múltiples géneros de vida y ocupaciones, todos los que son guiados por el Espíritu de Dios... según los dones y funciones que le son propios. Los Presbiteros, a semejanza del orden de los Obispos, cuya corona espiritual forman al participar de su gracia ministerial por Cristo, 
eterno y único Mediador, crezcan en el amor de Dios y del prójimo por el diario desempeño de su oficio.

Hay que tener también en cuenta el sentido de espiritualidad en cuanto crecimiento continuo en Cristo; es decir, que la espiritualidad supone una dinamicidad y un progreso continuos.

\subsection{Santidad Sacerdotal}

La santidad cristiana es la meta hacia la que se desarrolla progresivamente la vida espiritual. Con frecuencia se confunde este término con el de perfección cristiana.

La santidad es el don primero y fundamental que constituye el ser cristiano, el misterio de la gracia que hace de una simple creatura humana un hijo de Dios. En este sentido, en algunos pasos del N.T. los cristianos son llamados santos (Fil. 1,1). Estamos, pues, en el orden del ser.

La perfección, en cambio, se coloca en el orden del actuar y de las operaciones, designando más bien el desarrollo de un determinado ser incluyendo, por tanto, una cierta plenitud de vida: Sed perfectos como vuestro Padre Celestial es perfecto (Mt 5,48).

Inclusive el mismo Concilio Vaticano II habla indistintamente de santidad y de perfección (L.G., 5). El imperativo de la santidad y, por consiguiente el ideal, lo encontramos fundamentado en la realidad de lo que Dios es: Sed santos, porque yo Yahvéh, vuestro Dios, soy Santo. (Lev. 19,2).

Este imperativo de santidad es recogido por otros textos del Nuevo Testamento2 ${ }^{2}$. La santidad resulta, entonces, una exigencia del ser mismo del cristiano, y en especial del sacerdote que, como veremos, debe estar en función de Cristo, de la Iglesia y de los hermanos. De estos tres elementos y de la santidad de Dios mismo le vienen el origen y la necesidad de la santidad en su propio estado de vida: de parte de Cristo, con quien se configura, de parte de la Iglesia, de la que es ministro y de parte de los hombres, a los que va a servir y a santificar.

Toda la santidad del cristiano comienza por una iniciativa divina: el llamamiento y la consagración, que el sacerdote recibe con su vocación específica y con el sacramento del orden.

Lo que define al sacerdote (en el orden del ser), definirá también su santidad: su santidad será la del mediador con Cristo. Desde el momento en que el sacerdote es, por su ordenación, mediador de la única mediación de Cristo, es en la unidad de Cristo sacerdote, -hombre y Dios-, donde se realizará la unidad del sacerdote, hombre de Dios y hombre de los hombres.

21 Pe. 1, 16; 2,9; Rom 1,7; 8,28; Hebr. 7, 2-3. 
Partiendo del mediador único, se realizará en el sacerdote la armonía profunda de lo que Cristo espera de él en orden a su santidad personal y lo que espera en orden a la santificación de los demás.

\subsection{Fidelidad al Evangelio}

El Evangelio es la norma y el criterio último de la santidad y de la espiritualidad sacerdotal. El Evangelio es el punto focal de referencia de todas las actitudes espirituales que han de animar la vida del sacerdote:

Como ministros que son de la Palabra de Dios, diariamente leen y oyen esa misma Palabra de Dios que deben enseñar a los otros; y si al mismo tiempo se esfuerzan por recibirla en sí mismos, se harán cada día discípulos más perfectos del Señor (PO 13).

La pobreza, como la de María, es lo primero que como condición nos exige el Evangelio, porque la pobreza es apertura radical, es disponibilidad, es entrega. El Evangelio exige pobreza, no sólo como expresión del Reino, sino como actitud para recibirlo. Sólo a partir de una pobreza será posible comprometer definitivamente la fidelidad. De la pobreza surge la confianza (Mt 19. 26) y la confianza engendra la disponibilidad (LC 1,38).

El Evangelio sigue siendo una voz potente. En medio de un mundo secularizado que ponen, además, en crisis los valores más fundamentales del cristianismo y del sacerdocio, se podrá hablar de silencio, de oración, de cruz, de obediencia, de celibato, pero sólo si estamos ubicados en una perspectiva completamente diferente, que es la de la fe y la de la fidelidad radical al Evangelio. Fuera de esta perspectiva todo resulta oscuro y absurdo.

La exigencia que parte del Evangelio es absoluta: Ve, vende todo lo que tienes, ven y sígueme (Mt 19, 21); y la respuesta es igualmente absoluta: El que ha puesto la mano en el arado y vuelve la vista atrás, no sirve para el Reino de Dios (Le. 9. 62). Sólo en la plenitud de la fe, la misma fe que hizo feliz a María (Lc 1,45) puede captarse lo absoluto del llamamiento y la apertura vital de la santidad para el sacerdote.

La espiritualidad sacerdotal nace del Evangelio: manifestar a Dios en la totalidad de la vida; enseñar a los hombres cómo es posible aún la alegría, la esperanza, la fidelidad, la donación generosa a los hermanos. No tiene sentido la existencia sacerdotal sin una completa fidelidad al Evangelio, que implica silencio, soledad, anonadamiento y cruz, pero también resurrección. Ser fieles al Evangelio implica esencialmente vivir y comunicar la alegría profunda del misterio pascual (Card. Pironio). El sacerdote es el testigo, como los apóstoles, de la Resurrección del Señor.

La radical fidelidad al Evangelio supone que el Sacerdote incluye en su propia espiritualidad la actitud de María, Nuestra Señora: Felices más bien los que escuchan la Palabra de Dios y la ponen en práctica (Lc 11,28). 


\subsection{Sacerdocio y vida interior}

Recogiendo toda la riqueza de la tradición evangélica, el Concilio Vaticano II ha presentado la necesidad de la vida interior no sólo como raíz y alma del apostolado, sino también como parte mejor (Lc 10.42) y momento más alto de la existencia cristiana y sacerdotal.

El Concilio habla de santidad sacerdotal que se actúa mediante el Ministerio del Espíritu y de la Justicia; este ministerio se ve fecundado a su vez por la santidad personal:

La santidad misma de los presbiteros contribuye en gran manera al ejercicio fructuoso del propio ministerio; pues, si es cierto que la Gracia de Dios puede llevar a cabo la obra de salvación aún por medio de ministros indignos, de ley ordinaria, sin embargo, Dios prefiere mostrar sus maravillas por obra de quienes más dóciles al impulso e inspiración del Espíritu Santo, por su íntima unión con Cristo y la santidad de su vida, pueden decir con el Apóstol: 'Pero ya no vivo yo, sino que Cristo vive en mi' (Gál. 2,20) (cf. PO 12).

La esencia de la vida interior es la vida con Cristo en Dios (Col. 3,3 ), que se actúa penetrando siempre más a fondo en el Misterio de Cristo con el recogimiento y la Oración (PO 14); en esta vida interior Cristo es también el supremo modelo que hay que imitar. Esta imitación se realiza sobre todo como abundancia de la caridad que se dilata en donación a los hombres.

De ahí que uno de los elementos específicos de la espiritualidad sacerdotal es la dimensión apostólica en cuánto perfección de la caridad. La fuente interna del apostolado, es decir, la vida interior, presupone e incluye un íntimo conocimiento de Cristo.

La pastoral debe estar siempre adecuada a los modelos que va viviendo la Iglesia en su continua renovación, por medio de formas nuevas y cambios que suceden en la historia y en la Iglesia, cada cambio suscita o genera una corriente renovada de espiritualidad de acuerdo con la misma forma de los nuevos modelos de Iglesia; así, cada época ha tenido sus formas propias de espiritualidad. Ahora bien, la espiritualidad se puede entender como la motivación o las motivaciones evangélicas capaces de inspirar las experiencias humanas y cristianas en la Iglesia.

La vida interior, especialmente en la vida del sacerdote, debe ser hoy más esencial y más simple; es necesario simplemente transmitir al verdadero Dios que es el único que da sentido a todas las cosas. La vida interior es también un proceso de conocimiento de Jesús para poder conocer al verdadero Dios; si el sacerdote no conoce bien a Dios, lo entrega mal. En el fondo, el saber cómo es Dios supone hacer el proceso personal de conocer desde Abraham a Jesús. (Historia de Salvación, que se repite espiritualmente en cada hombre). Hoy más que nunca el sacerdote, que es evangelizador, debe 
ser contemplativo, a partir de una profunda vida interior; el contemplativo es aquel que tiene una verdadera experiencia de Dios en la fe, de toda su vida. Esto lo va a transmitir con un sentido misionero. La labor pastoral del Sacerdote en la Iglesia, sin la riqueza de la vida interior se vería privada de contenido, pero al mismo tiempo, en el contexto apostólico sacerdotal una espiritualidad que no se proyectara en un compromiso misionero sería pobre e incompleta. El sacerdote necesita fundamentar sus actitudes y actividades apostólicas, fundamentado en las exigencias evangélicas, responsablemente asumidas.

Toda la tradición teológico-ascética de la Iglesia es concorde en afirmar la esencial relación entre la íntima unión de pensamiento y de amor con Dios y apostolado.

Pero no es solamente el apostolado el que exige una fuerte vida interior; difícilmente se podrá perseverar en un intenso trabajo rico de espíritu sobrenatural, sin una profunda vida interior cuando se presentan las pruebas, las contradicciones, las persecuciones, que casi siempre acompañan la vida sacerdotal. Además, la vida interior es necesaria como condición de la gracia, indispensable para el apostolado. La vida interior, por tanto, es imprescindible como raíz íntima de una perfección integral en la vida sacerdotal, para no empobrecer la actividad apostólica de su impulso inicial de caridad sobrenatural.

El sacerdote tiene como tarea esencial la acción salvífica, en cuanto cooperador de Cristo en la Redención. Esta tarea exige una vida interior, que sea, además, de correspondencia a la personal vocación a la santidad, una adecuación con su dignidad y ministerio sacerdotal.

Con alguna frecuencia la exigencia de vida interior en la vida y ministerio del sacerdote se traduce en una necesidad de tomar la vida desde más arriba, de ir a lo esencial; lo cual muchas veces es entendido como una huída de la realidad humana, por todo lo que esta vida interior requiere de soledad, silencio, reflexión y oración. La vida interior supone una ascesis, unida al ejercicio de la oración; es decir, un ejercicio de la propia libertad para permitirnos hacer la paz en nosotros y con los otros, buscando la unidad de todos los elementos que componen la vida sacerdotal, que sólo es posible bajo la acción del Espíritu Santo.

Cuando se llega a descubrir la real importancia que tiene la vida interior, se ve la vida y el ministerio como un conjunto coherente en el que el espíritu se manifiesta a sí mismo. Al analizarse cerca las necesidades espirituales que el sacerdote experimenta, encontramos que, en variadas expresiones y formas, el sacerdote se une a la gran tradición espiritual de la Iglesia para los que se esfuerzan en dar a su vida unidad y consistencia. 


\section{UNIÓN CON CRISTO SACERDOTE}

La espiritualidad del sacerdote nace de la participación en la unción sacerdotal de Cristo, cabeza y pastor de la iglesia, en virtud del envío que Jesús hace de sus discípulos (JN 20,21-22), para la actividad pastoral en la misma Iglesia:

El sacerdote en la Iglesia:

\begin{tabular}{|l|l|}
\hline $\begin{array}{l}\text { 1.- Participa de Cristo, } \\
\text { Cabeza y Pastor. }\end{array}$ & $\begin{array}{l}\text { Enseñar, santificar, } \\
\text { apacentar }\end{array}$ \\
\hline $\begin{array}{l}\text { 2.- En virtud de la misión } \\
\text { apostólica confiada a los } \\
\text { discípulos }\end{array}$ & $\begin{array}{l}\text { Colaboración, comunión, } \\
\text { responsabilidad pastoral } \\
\text { (sacramento del orden) }\end{array}$ \\
\hline $\begin{array}{l}\text { 3.- En comunión con } \\
\text { la Iglesia y el Obispo }\end{array}$ & $\begin{array}{l}\text { Colaboradores (misión canónica), } \\
\text { obediencia, } \\
\text { consagrados (PO 5), celibato. }\end{array}$ \\
\hline
\end{tabular}

En los documentos del Concilio aparece claramente la idea de que el sacerdote puede y debe santificarse por la fuerza de su mismo sacerdocio, lo cual con otras palabras se puede expresar en dos formas: el sacerdote se santifica en unión con Cristo en el ejercicio de su ministerio y en la imitación de Cristo, sacerdote consagrado, santificado y enviado al mundo por el Padre (JN 10,36):

Cristo, a quien el Padre santificó o consagró y envió al mundo, se entregó a sí mismo por nosotros para redimirnos de toda iniquidad y purificar para sí un pueblo peculiar suyo, celador de buenas obras (Tit. 2,14) y así, por su pasión entró en la gloria; de semejante manera, los presbiteros, consagrados por la unción del Espíritu Santo y enviados por Cristo, mortifican en sí mismos las - obras de la carne y se consagran totalmente al servicio de los hombres y así, por la santidad de que están enriquecidos en Cristo, pueden avanzar hasta el varón perfecto" (PO 12).

La idea de la unión con Cristo la encontramos sugestivamente expresada en la imagen de la vid y los sarmientos. Si bien es cierto que esta alegoría del evangelio de san Juan vale para todos los cristianos, de manera muy particular la podemos encontrar aplicada al sacerdote.

\subsection{La vid y los sarmientos (Jn 15,1-8)}

Se trata de una alegoría en la que Jesús se pone a sí mismo como centro de la reflexión que propone. Su significado es explicado a base de precisiones, 
alusiones, etc. que con frecuencia interrumpen el desarrollo de la descripción alegórica.

La unión es el tema principal de este texto y de los textos que le siguen. Los cristianos pueden vivir sólo en Cristo. En Él está la fecundidad fructuosa en el verdadero servicio de Dios, de la oración que es escuchada y de la obediencia en el amor. Todos los que están en él son sus amigos, son los que han progresado en la amistad y el amor con El, y ellos están necesariamente unidos unos con otros.

El tema fundamental de la unión es después retomado y profundizado, bajo varios aspectos: el crecimiento de la unión, su necesidad, sus efectos, la suerte de los que no participan en esta unión, los cuales son cortados y arrojados fuera.

La unión entre Cristo y los suyos expresa la realidad de la vida de la Iglesia: la perspectiva eclesial, de manera particular en la línea del ministerio sacerdotal, resulta de una comprensión de la alegoría de la vid y los sarmientos.

De esta manifestación entendida y apreciada, partirá el movimiento ascendente de alabanza y glorificación de Dios por parte de los hombres: especialmente de aquellos que han sido considerados discípulos, amigos y colaboradores de la obra de Jesús, la verdadera Vid que da la vida eterna.

De este texto de San Juan podemos intuir la necesidad y la exigencia fundamental de la unión con Cristo por parte de cualquier cristiano, pero de modo particular, del sacerdote ministerial. Su relación con Cristo va orientada a la gloria de Dios y al servicio de los demás por medio de las buenas obras.

La vid, los sarmientos y los retoños forman un todo unido en un solo tronco; lo mismo sucede con los discípulos de Cristo. La unión de los discípulos con Cristo es el gran secreto de la Iglesia sobre la tierra y en el tiempo.

Los suyos, sus discípulos, no son abandonados a sí mismos, sino que están continuamente en la mano providente y benéfica del Padre. Dolores físicos y espirituales, desilusiones, fracasos, incomprensiones, soledad, lágrimas, renuncias, presentes siempre en la vida del sacerdote, constituyen un elemento de unión y abandono confiado en las manos del Padre.

El que permanece en mí y yo en él, ese da mucho fruto, a partir de esto se tiene, por revelación, la garantía de que la vida sacerdotal será fecunda, con la fecundidad de la paternidad espiritual, si está unida a Cristo; con frecuencia se quieren ver, tocar, constatar los frutos del ministerio en vez de creer, basados en la Palabra de Cristo, en la propia fecundidad ministerial. La unión esencial por medio de la Gracia, la unión afectiva por medio del amor, la unión espiritual por medio de la oración son los únicos factores decisivos aptos para fecundar una vida, especialmente cuando ésta es una vida sacerdotal. 
Esto implica en su esencia misma una acción de oblación en la identificación con Cristo:

Así al unirse los presbíteros al acto de Cristo Sacerdote, se ofrecen diariamente por entero a Dios y, al alimentarse del Cuerpo de Cristo, participan de corazón la caridad de Aquel que se da en manjar a los fieles. (PO 13).

Este texto habla en términos de amor y caridad sacerdotal, en cuanto vínculo de perfección y de unión hacia Dios y hacia el prójimo: caridad sacrificial y caridad pastoral, que es como el alma de toda una vida señalada por el hecho de la oblación de sí mismo a Dios en el Sacerdocio y de la que se desarrolla una espiritualidad especifica, configurada según las exigencias del propio sacerdocio. En esta línea se puede hablar de una espiritualidad sacerdotal cristocéntrica.

En el ejercicio de su ministerio el sacerdote actúa, en virtud del Sacramento del Orden, como causa instrumental o ministerial eficaz sólo en cuanto está relacionada y dependiente de la causa principal, que es Jesucristo, Sacerdote Sumo y Único. Este es el mensaje central de la alegoría de la Vid y los Sarmientos.

El carácter sagrado del sacerdocio establece un contacto fijo, didáctico y jurídico entre Cristo y el sacerdote que habla y actúa en nombre suyo. Por esta unión objetiva que es una real participación de poderes, el sacerdote cumple válidamente las funciones sagradas, aún en medio de la distracción o en estado de culpa.

La intimidad ministerial y la concausalidad de la gracia encuentran lógico desarrollo en la intimidad espiritual, en cuanto que el sacerdote no hace más que invocar el auxilio de Dios, buscar su voluntad y orientar todo a su gloria.

La tendencia a la perfección de la caridad en el sacerdote se orienta y concentra en Cristo sacerdote y victima, con un esfuerzo de conformación cada vez mayor con El en el pensamiento, en el amor, en la acción. En esta tendencia, el sacerdote se vacía cada vez más de sí mismo por el amor y entonces toda su actitud interior y exterior está caracterizada por una profunda humildad, resultado de la convicción de su instrumentalidad en relación a Cristo; de un espíritu de fe, que le hace percibir y respetar en sí mismo la grandeza de su sacerdocio; de la piedad por la que ora y trata las cosas sagradas, especialmente los divinos misterios; de la modestia, llena de sencillez y dignidad y del abandono generoso y constante en quien lo ha elegido y consagrado.

De esta manera se puede decir que la búsqueda de la perfección interior compromete al sacerdote en el ejercicio de todas las virtudes sobrenaturales.

La lógica del sacramento del orden, que consagra (separa) al sacerdote para 
Dios, exige que la santidad de Cristo sacerdote se refleje en su ser y en su vida. Jesucristo es el sacerdote, el único sacerdote, el sacerdote perfecto; su santidad coincide con su sacerdocio. El sacerdocio jerárquico es la prolongación, en la Iglesia, del sacerdocio de Cristo y por tanto, es necesario que sea una extensión de la santidad de Cristo.

Lo esencial lo encontramos aquí:

Los Presbiteros, por la unción del Espíritu Santo, quedan marcados con un carácter especial que los configura con Cristo Sacerdote, de tal forma pueden obrar en nombre de Cristo Cabeza (PO 2).

Todo lo de Cristo es criterio, norma y modelo para el sacerdocio, pero cabe resaltar tres aspectos de esta consagración del sacerdote en Cristo:

- El carácter insustituible de sus relaciones con Dios.

- El aspecto universal y eclesial de su sacerdocio.

- Y su proyección ministerial en favor de los hombres.

Sobre estos tres puntos nos detendremos en los siguientes apartados.

\section{EL SACERDOTE, HOMBRE PARA DIOS}

Lo absoluto del sacerdocio de Cristo, afirma el Cardenal Pironio 3 , es el carácter radical de sus relaciones con el Padre.

Cristo realiza múltiples actividades en favor de los hombres, porque le interesan los hombres y sus problemas, su liberación y su felicidad, pero fundamentalmente a Cristo le interesa el Padre. Su esfera es exclusivamente la del Padre: su voluntad, su gloria, etc. De ahí la importancia esencial del silencio, la soledad y la oración. La obediencia en el amor a la voluntad del Padre es el hilo conductor de toda su existencia. En esta misma línea, la configuración del sacerdote con Cristo debe estar igualmente orientada a la comunión personal con el Padre, en la búsqueda continua de su voluntad a través del ministerio y manifestada en la obediencia y comunión con el obispo. En este campo la oración tiene un puesto determinante: el sacerdote es un hombre para Dios.

\section{Jesús y el Padre (Jn 5,19-30)}

El tema fundamental de todo este texto evangélico lo encontramos contenido a manera de introducción en el versículo 17: Jesús les replicó: mi Padre trabaja siempre, y yo también trabajo.

Todo este tema está enmarcado por los versículos anteriores que nos narran la curación del enfermo paralítico en la piscina de Betesdá (Jn 5, 1-16).

3 Escritos Pastorales, BAC, p. 151. 
Existe un paralelismo estrecho entre el Padre y Jesús: el actuar del Padre es el mismo que el de Jesús. Está precisamente en esta relación de acción y de ser la razón última del actuar y del ser de Cristo.

Para poder entender en un contexto más amplio la importancia y el alcance de esta estrecha relación de Jesús con su Padre proyectada en la vida del sacerdote, sería necesario añadir y comparar el texto más o menos paralelo de JN 14,10-12. Hablar de la acción del sacerdote es hablar necesariamente de una comunión y participación en el Misterio de amor de Dios que amó tanto al mundo que le envió a su Hijo único $(\mathrm{JN} 3,16)$. No tiene sentido el sacerdocio si no es en el contexto del amor. El sacerdote capta el amor que Dios le tiene y por eso le comunica la misma misión de Cristo: Como el Padre me envió, así también yo os envío a vosotros (JN 20, 2 I); por eso el sacerdote expresa el amor del Padre, y colabora con El realizando y continuando, bajo la acción del Espíritu, la misma misión que el Padre le encargó a Cristo; en ese mismo sentido el sacerdote puede decir: Mi Padre trabaja y yo también trabajo y así, puede incluso hacer obras mayores.

El Sacerdote, como Cristo, no puede ser comprendido y aceptado sino desde la fe, en su relación personal con el Padre. La fe nos coloca la figura y la persona del Sacerdote en el corazón mismo del Misterio Divino, que es misterio de amor.

El Espíritu consagra al sacerdote para la vivencia del amor en el gozo de la comunión filial; si la indiferencia o la frialdad secan y agotan su corazón, no puede vivir su consagración total a Dios; sólo en el amor es posible el gozo del celibato sacerdotal.

En la perspectiva de la comunión de acción y de ser con el Padre nace la exigencia de profundidad interior, de silencio, de oración, porque el Sacerdote es el hombre para Dios, el signo del amor del Padre para los hombres.

\section{El silencio}

El silencio es la perspectiva que posibilita el encuentro. Silencio no significa sólo la ausencia de sonidos, de ruidos o de voces; el silencio es lo que resulta cuando el hombre, después de haber hablado, regresa a sí mismo y calla.

El hombre, el sacerdote, puede encontrar respuesta a tantas preguntas sólo en el silencio, en el callar luminoso del interior, en la más profunda calma de la propia existencia, de donde las cosas y los acontecimientos son nombrados y determinados por una voz sin voz, por una palabra sin palabra: desde adentro del silencio del absoluto, de Dios en Cristo.

El silencio es la experiencia de la presencia de Dios. Cristo ve, oye, entiende al Padre, desde la eternidad de su propio silencio divino, por eso Cristo es el Revelador: La Palabra estaba en Dios (Jn 1, 1) sólo después se manifiesta y es la revelación del Misterio envuelto por el silencio en los siglos eternos (Rom 16, 25). 


\title{
Espiritualidad sacerdotal
}

Es necesario poner silencios, descanso y esperanza en nuestra actividad, en nuestros pensamientos, en nuestros sentimientos, en nuestro cuerpo. A partir del silencio empieza a surgir un nuevo, creador, renovador encuentro consigo mismo y con el Señor. Los niveles de comunicación con Dios no pueden nacer sino de silencios cada vez más profundos.

El silencio de Dios es plenitud de vida, es presencia experiencias que invade el espíritu; pero también el silencio, en ocasiones puede manifestarse a manera de vacío y de tormento, que Rabindranath Tagore experimenta en su oración:

\author{
Señor mío, hace muchos días que la lluvia \\ no ha caído sobre mi árido corazón. \\ El horizonte está desnudo y es cruel... \\ Mitiga, oh Señor, mitiga este calor silencioso que todo lo invade, \\ que lento, agudo y cruel hace arder el corazón \\ en una terrible desesperación. \\ Deja que la nubecilla de la gracia se incline desde lo alto \\ como la blanda mirada de la madre en el día de la ira paterna.
}

El silencio es el punto de partida de un progreso de interiorización hacia nosotros mismos y de disponibilidad para lo divino y su manifestación en nosotros. El silencio es un trabajo esencial que hay que realizar para elevarnos a los niveles que nos corresponden; el silencio es la aventura de toda la persona a través de un encuentro, una presencia, una profundización y una liberación. El sacerdote, a través de su silencio, podrá ser presencia y testimonio de Aquel que 'tiene la vida en sí mismo' (JN 5, 26).

\section{La oración}

Hacer silencio es entrar en la propia profundidad, orar es entrar en la profundidad de Dios, en el silencio de Dios.

La oración es un fenómeno primario de la vida espiritual; es el gesto central, el corazón, lo que distingue al hombre de Dios, al sacerdote, al religioso. En la oración de Cristo (Padre mío) se expresa la unión misteriosa e íntima con su Padre: la oración de Cristo es la expresión de su ser de Dios, de su ser con Dios y de su ser para Dios y, desde Dios, para los hombres. Jesús enseña a sus discípulos a orar porque los hace participar de su propio misterio de comunión con el Padre y de cumplimiento de la misión.

La oración en la vida del sacerdote pastor no es un elemento más; no es solamente una fuente de energía para su actividad pastoral, sino que es parte de ella. La oración es el momento privilegiado de la vida y actividad del sacerdote.

Mucho se podría decir a propósito de la oración; se han escrito miles de libros. Valga insistir por ahora solamente en la dimensión que es necesario subrayar, de la vida contemplativa en la vida de los presbíteros, que a pesar 
de sus limitaciones de tiempo por sus actividades pastorales, prioritariamente deben ser hombres de Dios, hombres para Dios, como Jesús, como María: contemplativos en la acción. El sacerdote hoy, en su tarea de evangelizar, debe ser un contemplativo, o sea, aquél que tiene una experiencia real, personal de Dios en la fe que abarca toda su vida y que transmite con su alegría, su trabajo, su testimonio, su palabra, su apostolado a todos los demás hombres, hermanos suyos en la fe.

El problema en la oración del sacerdote está ligado a su modo propio de vivir. Hay estilos de vida, sin ningún control ni disciplina personal, psicológicamente incompatibles con actividades que exigen el ejercicio de la fe, como la oración. Si ello no existe no tendremos la libertad necesaria para un encuentro con Dios auténticamente contemplativo. Hace falta la disciplina de vida, es indispensable tener un mínimo de auto-control para ser fieles a la oración.

En esta misma línea es muy elocuente el pensamiento de Juan Pablo II expresado en su carta a todos los sacerdotes con ocasión del Jueves Santo de 1979:

Nuestra tarea es la de servir a la verdad y a la justicia en las dimensiones de temporalidad humana, pero siempre dentro de una perspectiva que sea la de la salvación eterna. (... ) Los hombres, nuestros hermanos en la fe y también los no creyentes, esperan de nosotros que seamos capaces de señalarles esta perspectiva, que seamos testimonios auténticos de ella, que seamos dispensadores de la Gracia, que seamos servidores de la Palabra de Dios. Esperan que seamos hombres de oración (n. 19).

La insistencia del Papa sobre el tema para los sacerdotes nos habla de la importancia capital que la oración tiene en la vida del sacerdote; continúo transcribiendo trozos de su carta a los sacerdotes:

No ha habido bastante valor para realizar el mismo sacerdocio a través de la oración, para hacer eficaz su auténtico dinamismo evangélico, para confirmar la identidad sacerdotal. Es la oración la que señala el estilo esencial del sacerdocio... La oración nos ayuda a encontrar siempre la luz... La oración nos permite convertirnos continuamente, permanecer en el estado constante de tensión hacia Dios, que es indispensable si queremos conducir a los demás a El. La oración nos ayuda a creer a esperar y a amar ${ }^{4}$.

La oración, podemos afirmarlo, da sentido y llena de plenitud y gozo la existencia sacerdotal, que de otra manera se vería privada de su verdadera riqueza de contenido para el testimonio ministerial: El Hijo no puede hacer

4 Juan Pablo II, a los Sacerdotes con ocasión del Jueves Santo, 1979, p. 30. 


\section{Espiritualidad sacerdotal}

nada por su cuenta, sino lo que ve hacer al Padre; lo que hace Él eso lo hace igualmente el Hijo, porque el Padre quiere al Hijo y le muestra todo lo que El hace (JN 5,19-20).

La oración para el sacerdote es también la ventana o la puerta de acceso a la intimidad con Cristo, a la verdadera amistad con él, para saborear los secretos del Padre: Vosotros sois mis amigos si hacéis lo que yo os mando. Ya no os llamo siervos, porque el siervo no sabe lo que hace su Señor; yo os llamo amigos, porque os he revelado todo lo que aprendí de mi Padre (JN 15,15).

El sacerdote es alguien que debe comunicar constantemente a Dios y con Dios; que lo exprese en su palabra, en sus gestos, con su presencia, que lleve a los hombres a Dios. El sacerdote, por su intimidad con el Padre, por la acción del Espíritu, es quien traduce las penas, las alegrías, los temores, los anhelos y todas las realidades de los hombres y las transforma en oración. Por eso, hecho uno con Cristo, es, a impulsos del Espíritu, el hombre para Dios, de donde descubre su más profunda identidad: ser testigo de Dios para los hombres.

\section{SU PERTENENCIA A LA IGLESIA}

Una de las principales características de la espiritualidad del Sacerdote es la dimensión eclesiológica: su pertenencia activa a la Iglesia; el sacerdote es un edificador de la Iglesia (Cfr. Rom 15, 20; 1 Cor 3, 9; 2 Cor 10, 8; 12,19; 13, 10; Ef 2,$21 ; 4,12)$, un ministro. El Concilio ha resaltado esta dimensión eclesial del sacerdocio, encuadrando el orden sagrado y la condición del presbítero dentro de la misión de la Iglesia, que recibió de Cristo por el don del Espíritu; el mismo sacerdocio se define y explica por la pertenencia a la Iglesia.

El Señor Jesús... hace partícipe a todo su cuerpo místico de la unción del Espíritu con que Él fue ungido, pues en él todos los fieles son hechos sacerdocio santo y regio, ofrecen sacrificios espirituales y pregonan las maravillas... No se da por tanto, miembro alguno que no tenga parte en la Misión de Cristo, sino que cada uno debe santificar a Jesús en su corazón y debe dar testimonio de Jesús con espíritu de profecía. Ahora bien, no todos los miembros desempeñan la misma función (Rom 12,4).

... de entre los mismos fieles, instituyó a algunos para ministros, que en la sociedad de los creyentes desempeñaran y poseyeran la sagrada potestad del orden para ofrecer el sacrificio y perdonar los pecados y desempeñarán públicamente el oficio sacerdotal por los hombres en nombre de Cristo. Así pues, enviado los apóstoles, como El fuera enviado por su Padre, Cristo, por medio de los mismos apóstoles, hizo partícipes de su propia consagración y misión a los sucesores de aquellos que son los obispos, cuyo cargo minis- 
terial, en grado subordinado, fue encomendado a los presbíteros, a fin de que, constituidos en el orden del presbiterado, fuesen cooperadores del orden episcopal para cumplir la misión apostólica confiada por Cristo... El ministerio de los presbíteros, por estar unido con el orden episcopal, participa de la autoridad con que Cristo mismo edifica, santifica y gobierna su cuerpo... Los presbíteros, por la unción del Espíritu Santo quedan sellados por un carácter particular y así, se configuran con Cristo sacerdote, de suerte que puedan obrar como en persona de Cristo cabeza (PO2).

Para descubrir e iluminar la dimensión eclesial de la espiritualidad del sacerdote, en cuanto que es participación de la misión misma de Cristo y consagración del Espíritu para el servicio, analicemos brevemente el texto de la misión confiada a los discípulos por Jesús después de la Resurrección.

\subsection{El Espíritu Santo y la misión (Jn 20,19-23)}

El punto de partida de todo el mensaje contenido en este pasaje del Evangelio de Juan es la aparición de Cristo a sus discípulos: Jesús vive y está con sus amigos (Jn 15,14-16), aquellos a quienes ha asociado a su misión recibida del Padre.

La escena tiene lugar en Jerusalén el mismo día de la pascua, es decir, en el mismo escenario y tiempo en que se ha realizado la plenitud de la misión de Jesús: Así habló Jesús y alzando los ojos al cielo dijo: 'Padre ha llegado la hora; glorifica a tu Hijo, para que tu Hijo te glorifique a ti'.

Cuando Jesús ha cumplido ya totalmente la misión encomendada por el Padre, es cuando comienza la tarea y la misión de la Iglesia, animada por el Espíritu Santo. Por la fe en Jesús resucitado los discípulos habrán de continuar y prolongar la misión que Jesús recibió de su Padre; su tarea fundamental será la de ser testigos de la resurrección; por eso Jesús se les aparece. La fe de los discípulos se basa en la presencia real del Señor viviente, reconocido como el crucificado de ayer.

El envío de los discípulos es paralelo al de Jesús. Pero el evangelista no solamente compara dos realidades; lo importante aquí es que Jesús hace partícipes a los suyos de su:

* Vida: Lo mismo que me ha enviado el Padre que vive, y yo vivo por el Padre, así también el que me coma vivirá por mi $(\mathrm{Jn} 6,57)$

* Conocimiento: Como me conoce el Padre y yo a El, yo conozco mis ovejas y las mías me conocen a mí. (Jn 10, 14-15)

* Amor: Como el Padre me ama, yo también os he amado a vosotros (Jn 15, $6)$.

* Misión: Como tú me has enviado al mundo, yo también los he enviado al mundo. (Jn 17,18) 
Los apóstoles (apóstol = enviado) deben ahora, como Jesús, buscar y cumplir siempre la voluntad del Padre (Cfr. Jn 4, 31-38). Se abre una nueva fase de la historia de la salvación: la obra de Cristo se continuará en las obras, aún mayores $(J n$ 14,12) de sus discípulos. Existe, pues, una identidad de mision entre Cristo y sus apóstoles.

De ahí que del paralelismo que se puede establecer del sacerdote con los apóstoles, deriva la continuación real en el tiempo de la Iglesia de la única misión de Cristo confiada a los apóstoles.

La fe del sacerdote, vivida profundamente con un sentido de pertenencia a la Iglesia, es una fe pascual; su vida es testimonio (Hemos visto al Señor) y presencia de Cristo resucitado, al mismo tiempo que es signo del amor del Padre para unir, y es 'encarnación' de la acción del Espíritu para la santificación de los hombres en medio de la comunidad.

De este modo el sacerdote es en la Iglesia inspirador de la comunidad para que ésta sea capaz de recordar (Jn 14, 26) la Palabra de Jesús; el sacerdote es el profeta que anima a la comunidad y anuncia la Palabra con el poder de Dios. El sacerdote es también, -como el Espíritu-, el consolador que alienta y conforta a la comunidad eclesial y el que la guía como Pastor y presidente de la asamblea, especialmente en las celebraciones litúrgicas.

El sacerdote es el que engendra a la fe en Cristo resucitado a la comunidad que preside por su identidad de misión con la de Jesús, su señor y maestro.

\subsection{Consagrados por el Espíritu}

El don del Espíritu, unido a la misión de los discípulos, es real.

Por consiguiente, los presbíteros están llamados a servir al pueblo de Dios y constituyen con los obispos un único cuerpo sacerdotal, aunque destinado a diversos oficios.

En el ejercicio de estos oficios, puesto que los presbíteros participan por medio de los obispos del único sacerdocio de Cristo, no son meros ejecutores de las órdenes del obispo: Síguese que por el don del Espíritu Santo que se ha dado a los presbíteros en la sagrada ordenación los obispos los tienen como colaboradores y consejeros necesarios en el ministerio y oficio de enseñar, santificar y apacentar el pueblo de Dios" (PO, 7).

El Espíritu Santo actúa en toda la Iglesia, por tanto, todos tienen parte en la misión de la Iglesia, que para los sacerdotes se especifica por me dio del obispo. Así, la participación del ministerio episcopal tiene dos momentos: la ordenación (que da la capacidad de realizar el ministerio que ahí nace; cfr. 2 Cor 3,5$)$ pero que se actúa en un segundo momento, el de la misión canónica. El sustrato de toda esta participación es la comunión con el obispo, que está también en la base de la estructura sacramental de la Iglesia. 
Podemos concluir este apartado reafirmando la pertenencia del sacerdote a la Iglesia. El sacramento del orden lo injerta íntimamente en la Iglesia con una función pública, en virtud de una comunión jerárquica con todo el cuerpo místico de Cristo.

Por otro lado, el Concilio Vaticano II, al poner de relieve el espíritu del sacerdocio como un servicio realizado en favor del pueblo de Dios, insiste en la participación en la caridad del Buen Pastor, que lo impulsa a dar su vida por el rebaño. Esto mismo subraya nuevamente la estrecha relación del sacerdote con la Iglesia, la eclesialidad de su vida y la sintoniza de su espíritu con el sentir, el pensamiento, la esperanza y la acción de toda la Iglesia.

Así, como notas históricas, distintivas del carácter eclesial del sacerdote, podemos enumerar la unidad, la catolicidad, la apostolicidad y la santidad. Esto significa al mismo tiempo que el sacerdote va poco a poco, configurándose en todo su ser con la realidad misteriosa de la Iglesia, sabiendo que pertenece más a la Iglesia que a sí mismo y que se santifica a sí mismo en la medida de su servicio y de su dedicación a los intereses del Reino de Dios.

\section{EL MINISTERIO SACERDOTAL}

La espiritualidad del sacerdote, siendo fundamentalmente cristológica y eclesial, es también apostólica, en el sentido de una reproducción, en el sacerdote, del espíritu de los apóstoles, que presidían las primitivas comunidades cristianas en la oración, la comunión, el servicio de la Palabra y la fracción del pan (Hech 2,42-47; 4, 32-35; 1 Pe 5, 3; Fil 3, 17; 2 Tim 1,13). Su ministerio apostólico es siempre en favor de los hombres: Los presbíteros, tomados de entre los hombres y constituidos en favor de los hombres en lo que a Dios se refiere para que ofrezcan dones y sacrificios por los pecados... (PO, 3).

El sacerdote está llamado a actuar en su vida sobre todo la vivencia espiritual de los apóstoles, vitalidad de su acción jerárquica, que lo ha de impulsar en el camino de la santidad a través de su propio ministerio. Esta es otra de las características de la espiritualidad sacerdotal: el apostolado es fuente de santificación:

Los presbiteros del Nuevo Testamento, por su vocación y ordenación, son en realidad segregados, en cierto modo, en el seno del pueblo de Dios; pero no para estar separados... sino para consagrarse totalmente a la obra para la que el Señor los llama. No podrían ser ministros de Cristo si no fueran testigos... ni podrían tampoco servir a los hombres si permanecieran ajenos a la vida y condiciones de los mismos. Su propio ministerio exige por título especial que no se configuren con este siglo; pero requiere al mismo tiempo que vivan en este siglo entre los hombres y como buenos pastores conozcan a sus ovejas... (PO, 3). 
No significa esto que la única fuente de santificación para el sacerdote ministerial sea el apostolado, ya que éste debe ser realizado en el Espíritu de Cristo. Será ciertamente de su relación con Cristo, como efusión de un amor cotidianamente purificado y consagrado en la oración y en la contemplación de los divinos misterios que encuentre una fuerza y una vitalidad su propio apostolado. La imagen del Buen Pastor puede iluminar nuestra reflexión.

\subsection{El Buen Pastor (Jn 10,1-18)}

La imagen del pastor era ciertamente familiar para los israelitas; Dios es Ilamado pastor de su pueblo; el rey David era pastor y es figura del Mesías. En este texto san Juan reúne tres parangones sobre la figura del pastor, unificándolos: Jesús es pastor, es la puerta y es buen pastor. Son las tres partes en que se divide este texto.

Jesús es pastor. Aquí se describen las actitudes y actividades del pastor: abre el aprisco, llama las ovejas y ellas oyen su voz, las llama por su nombre, las saca afuera, camina al frente de ellas, las ovejas le siguen. En cambio, ante el pastor falso, las ovejas huyen porque no lo conocen (no lo reconocen; en el versículo 6 se alude claramente a los falsos pastores de Israel: los fariseos. Las ovejas son recogidas en el aprisco que simboliza a la Iglesia; ante las ovejas, de manera simbólica Jesús hace un elenco de cualidades que han de tener los pastores y sus distintas funciones.

Jesús es la puerta. No hay salvación sino por medio de Cristo. El ha sido enviado para transmitir la vida; los otros son lo contrario; asesinos. Aquí se resume la misión de Cristo recibida del Padre, Que tengan vida; y esa vida es precisamente el conocimiento que las ovejas tienen de Dios: Ellas conocen mi voz (esta es la vida eterna, que te conozcan a tí, único Dios verdadero y a tu enviado Jesucristo, Jn 17, 3). Cuando se habla de entrar y salir de las ovejas, se está utilizando una fórmula bíblica que indica la libertad del creyente (Cfr. Núm 22, 17; Deut 28, 6).

Jesús es Buen Pastor. Jesús no sólo viene a dar la vida, sino que viene a entregar su vida; esta es la idea que aparece a través de la imagen del buen pastor (literalmente: el pastor hermoso. El término utilizado, en su contexto, da la idea de las condiciones necesarias para dar la vida y ser un buen pastor: la bondad, la nobleza, la perfección. La imagen del buen pastor es prerrogativa de Yavé en el Antiguo Testamento (cfr. Miq 5, 3; Ez 34, 23-31; Zac 13, 7-9) y es aplicada a Jesús, que al mismo tiempo se revela a sí mismo en su condición divina por el uso de la expresión Yo soy (cf. Ex 3,14). Se presenta aquí el paralelismo entre Cristo y sus ovejas y el Padre y Cristo; existe una comunión de conocimiento y de vida. Al hablar de otras ovejas se alude al universalismo de la salvación.

La imagen del buen pastor no es una imagen de ternura y sentimentalismo, sino la imagen del guía y del rector desinteresado del pueblo de Dios. Esta 
imagen pone el acento sobre ciertos aspectos del pastor y su misión con las ovejas: es el que conduce a las ovejas; el que las une (sentido de participación en la intimidad divina); las sirve dando su vida voluntariamente. por ellas (servicio de salvación).

La figura del buen pastor tiene una gran importancia sobre todo para los llamados pastores de la Iglesia. Precisamente ahora, en la época de la participación cada vez más activa de los laicos en el trabajo apostólico, esta figura asume para todos un significado que no es puramente pasivo (conciencia de sentirse protegidos por Cristo), sino sobre todo, activo, o sea, nos muestra el trabajo y la responsabilidad que el pastor tiene en relación a los demás.

\subsection{Al servicio de los hombres}

Uno de los aspectos que marcan más claramente la espiritualidad del sacerdote hoy es su condición de servidor, a imitación de Cristo el buen pastor, que no vino a ser servido, sino a servir (Mt 20, 28).

No hay más que un modo de servir a los hombres; sirviendo a Jesucristo; y no hay más que un modo de servir a Jesucristo; sirviendo a los hombres.

Servir es dar la vida. Lo primero que nos exige el servicio a los hombres es que los sintamos verdaderamente hermanos, a impulsos de la caridad de Cristo, para compartir, con un corazón indiviso y libre sus penas y dolores, sus angustias y tristezas, sus alegrías y esperanzas.

Esto supone, -afirma el Card. Pironio-, una personalidad humana muy rica donde se desarrolle el sentido sagrado de los auténticos valores humanos; la sinceridad y la justicia, la firmeza y la fidelidad, la sencillez y la amistad, el desprendimiento y la generosidad, la alegría y el equilibrio, el coraje y la lealtad.

Pero sobre todo el modo especifico de servir es como ministro de la palabra, de la Eucaristía, de la caridad, haciéndose servidor abierto de la Palabra, ofreciéndose como víctima en el sacrificio, dando su vida como buen Pastor por sus ovejas y presidiendo la unidad y la caridad en el servicio de autoridad que ha recibido de Cristo.

Por eso el ministerio del sacerdote es esencialmente santificador, porque participa directamente de la caridad de Dios en Cristo.

Esta caridad es la del buen pastor que conoce personalmente a sus ovejas y señala la profundidad espiritual de la donación a los hombres.

La caridad del ministerio sacerdotal es el vínculo de perfección $(\mathrm{Col} 3,14)$ que lleva al sacerdote, en el ejercicio de su ministerio, a la verdadera santidad, iluminando y dando sentido a su pobreza sacerdotal, a su consagración en el celibato, a su obediencia de comunión y a su actitud contemplativa. 
Sólo en un contexto vital de amor activo pastoral puede ser entendida la virginidad consagrada: como amor absoluto y total, como verdadera paternidad espiritual: El Celibato es signo y estímulo de la caridad pastoral y fuente peculiar de la fecundidad espiritual en el mundo (PO 16).

La vivencia de la caridad pastoral a través de la obediencia, la pobreza, el celibato, la contemplación, la donación a los hermanos, es la forma sacerdotal de vivir, haciéndolo nuestro, el fiat de María, unido al si de Cristo a la voluntad del Padre en el misterio pascual.

El sacerdote es el hombre para Dios que se santifica viviendo la alegría del misterio pascual a través de su ministerio, en su condición de hombre para los hombres.

\section{MARIA Y EL SACERDOCIO}

Valga simplemente, para concluir este estudio sobre la espiritualidad sacerdotal, decir una palabra sobre María en la vida del sacerdote; simplemente una palabra, ya que no es poco lo que sobre este tema se ha escrito.

En su misión de santificador del pueblo de Dios, el sacerdote está ligado a María en su maternidad de Gracia. Por el hecho de que María, por el fiat de la encarnación, recibió en su seno a Cristo, cabeza de la humanidad, recibió también radicalmente a todos los miembros de esta cabeza.

En la maternidad espiritual, el sacerdote, incorporado a Cristo cabeza, participa de manera especial de los frutos de gracia que esta maternidad de María trae a la iglesia, puesto que el sacerdote prolonga de alguna manera el ser mismo de Cristo Sacerdote.

El sacerdote en su ministerio debe contar siempre con el apoyo y la acción de María como Madre de todos los que son hermanos de Jesucristo.

El sacerdocio de Cristo estuvo, desde luego, enriquecido por la presencia maternal de María, su madre. La hora y el ministerio del sacerdote hoy en la Iglesia, debe estar - de hecho lo está- enriquecido por esa misma presencia de aquella que es nuestra madre y señora.

La imitación de la pobreza, de la generosidad, de la alegría, de la total donación de María al Padre celestial será para el sacerdote el camino más fácil, ya experimentado, ya recorrido, para llegar al Padre: María lo ha recorrido.

La fidelidad a la Palabra y el silencio contemplativo de La hija predilecta del Padre, nos impulsan a los sacerdotes en el camino de la fidelidad al evangelio y a la unión vital con el Padre. Para servir a los hombres es necesario comprender la acción de Dios, como María: María, por su parte, guardaba todas estas cosas, y las meditaba en su corazón (Lc 2,1). Es necesario también vivir la disponibilidad de María para cumplir siempre la Voluntad del Padre y encontrar en ello la felicidad: Dichosos más bien los que oyen la Palabra de Dios y 
la guardan (Lc 11, 28). Dichosa tú porque has creído (Lc 1, 45).

La mejor orientación para la vida y el ministerio de los sacerdotes la encontramos también en labios de María, Nuestra Madre, y con eso que damos definitivamente orientados y cerramos en palabras de María nuestra reflexión sobre la espiritualidad sacerdotal:

\section{Hagan lo que él les diga (Jn 2, 5)}

\section{Excursus sobre la espiritualidad sacerdotal según la Exhortación Pastores dabo vobis del Papa Juan Pablo II}

Después de un buen tiempo de haber aparecido la exhortación apostólica postsinodal del Papa Juan Pablo II sobre el sacerdocio y la formación sacerdotal, hoy podemos profundizar un poco más en su contenido y alcances para comprender y vivir mejor nuestra espiritualidad sacerdotal.

Tal vez alguna expectativa se proyectaba suponiendo un documento que superara la Presbyterorum Ordinis, la Optatam Totius o la Ratio Fundamentalis Institutionis Sacerdotalis, cosa que no podría ser, dada la naturaleza de todos estos documentos. Pero sí era muy importante una orientación renovada en relación a la identidad, la espiritualidad y el estilo de vida de los presbíteros en el contexto de la Iglesia de hoy.

El texto de la exhortación, se podría decir, se orienta sobre dos líneas básicas, que son la identidad sacerdotal y espiritualidad sacerdotal; la primera afrontada más en la perspectiva teológica y la segunda en la perspectiva más práctica y pastoral. Tratemos de analizar un poco estos dos aspectos.

\section{La identidad sacerdotal}

La teología del presbiterado gira básicamente en torno a dos ejes: Cristo y la Iglesia. Hay quien ha exagerado alguno de estos dos aspectos, independizándolos uno del otro, reduciendo de esta manera la teología del presbiterado y presentando consiguientemente una visión parcial del mismo. EI Papa elabora una delicada síntesis teológica (Cap. II), que en la práctica no siempre es fácil lograr, la cual sirve de base para una reflexión sobre la espiritualidad y la formación del presbitero.

Esta doble relación, -con Cristo y con la Iglesia-, sitúa al presbítero no sólo en la Iglesia, sino al frente de la Iglesia (PDV, 16). El Santo Padre indica cómo el ministerio del presbítero está totalmente al servicio de la lglesi" (ib), por razón de que el sacerdote representa sacramentalmente a Cristo cabeza, pastor y esposo de la Iglesia.

El Presbítero, transparencia de Cristo, está llamado a apacentar a la Iglesia; esta imagen, la del pastor, es la propia del sacerdote. De ahí deriva el título 


\section{Espiritualidad sacerdotal}

de la exhortación.

Pastor, por tanto, imagen de Cristo, vive una eclesiología de comunión, por que su ser sacerdotal y por tanto su identidad, están basados en el misterio de comunión trinitaria. Su manera propia de realizar esta comunión es en una tensión misionera, proyectando este misterio, del cual participa, a los hombres 5 .

Un aspecto muy significativo de la identidad presbiteral, sobre el que insiste el Papa, es la forma comunitaria del Ministerio: El ministerio ordenado tiene una radical 'forma comunitaria', y puede ser ejercido sólo como una 'tarea colectiva' (PDV, 17). Este aspecto subraya la inserción en el presbiterio y el consiguiente compromiso estable con una Iglesia local. Estamos hablando de un elemento que por su naturaleza es esencial al ministerio y no puede ser considerado como accesorio o accidental al mismo; la esencia pastoral del ministerio exige que éste se realice en un clima espiritual de verdadera unidad, con el Obispo, con el presbiterio, con los fieles. De ahí que se puede hablar con fundamento que el carisma, nacido del Sacramento del Orden, propio del presbítero, es el carisma de la unidad.

\section{La espiritualidad sacerdotal}

La espiritualidad sacerdotal es abordada con bastante amplitud en el capítulo III del Documento y se estructura en base al concepto fundamental de vocación a la santidad. El Papa parte de la idea expresada en los Documentos del Concilio (LG cap. V) y va poco a poco aplicando esta idea a la vida y el ministerio de los presbíteros.

La espiritualidad deriva de la identidad del sacerdote: Una formación espiritual común a todos los fieles, pero que requiere ser estructurada según los significados y características que derivan de la identidad del presbítero y de su ministerio (45). Ésta se alimenta de la relación ministerial con Cristo, cabeza y pastor, siervo y esposo de la Iglesia, que le lleva a ser signo en favor de su pueblo. Esto quiere decir que todos los carismas de que pueda gozar un presbítero han de ser adecuadamente integrados en la figura del pastor, o sea, de servidor que da la vida por sus ovejas. Ningún carisma puede sobreponerse a este carisma fundamental del presbítero, sintetizado todo esto en la caridad pastoral.

Es notable el énfasis que el Papa pone en la identificación con Cristo esposo

5 En efecto, el presbítero, en virtud de la consagración, que recibe con el sacramento del orden, es enviado por el Padre, por medio de Jesucristo, con el cual, como cabeza y pastor de su pueblo se configura de un modo especial para vivir y actuar con la fuerza del Espíritu Santo al servicio de la Iglesia y por la salvación del mundo (PDV, 12). 
de la Iglesia; aunque también se habla de la espiritualidad el siervo y del hermano.

\subsection{La espiritualidad del Esposo}

La espiritualidad del sacerdote no se define como renuncia al sexo, al dinero o a otro tipo de cosas, sino como donación libre de amor a Cristo y a la Iglesia. Aquí radica la vivencia de los consejos evangélicos, animados siempre por la caridad pastoral6. Es muy sugestiva esta expresión del Papa, referida a la espiritualidad propia del sacerdote; inspirado en Ef 5,22-32, aplica a la vivencia sacerdotal lo que tradicionalmente fue aprovechado para la espiritualidad matrimonial. En el sacerdote también se realiza es grande Misterio...referido a Cristo y a su Iglesia... Esta misma idea la aprovecha el Papa para explicar el sentido del celibato ministerial y dice: La Iglesia, como Esposa de Jesucristo, desea ser amada por el sacerdote de modo total y exclusivo, como Jesucristo, Cabeza y Esposo, la ha amado (29). Esto ayuda a expresar más claramente la relación que existe entre el celibato y el ministerio sacerdotal. Como consecuencia de esta identificación con Cristo-Esposo, el sacerdote se entrega, con amor esponsal al servicio de la Iglesia, como Cristo, que se entregó a sí mismo por ella (Ef. 5, 25). El Sacerdote, - sigue diciendo el Papa -, está al frente de la Iglesia para alimentarla y cuidarla; llegando a ser así imagen viva de Jesucristo, Esposo de la Iglesia y revivir en su vida espiritual el amor de Cristo-Esposo con la IglesiaEsposa. Esto exige al sacerdote servir con entrega total, continua y fiel.

\subsection{La espiritualidad del Siervo}

Es la espiritualidad del que sabe que es enviado para dar su vida por el rebaño, es el buen pastor que da la vida por sus ovejas. El presbítero ha recibido un poder de lo alto para ponerlo al servicio de la comunidad. Su santificación la realiza por medio del ministerio 7 . El sacerdote es servidor, no dueño; recibe la Palabra de Dios para darla al pueblo, pero él debe ser el primero en acogerla, para que lo invada y hacerse así transparencia, anuncio y testimonio del Evangelio.

6 El sacerdote que recibe la vocación al ministerio, es capaz de hacer de éste una elección de amor, para el cual la Iglesia y las almas constituyen su principal interés y, con esta espiritualidad concreta, se hace capaz de amar a la Iglesia Universal y a aquella porción de Iglesia que le ha sido confiada, con toda la entrega de un esposo hacia su esposa (PDV, 23).

${ }^{7}$ Así, desempeñando el oficio de buen pastor, en el mismo ejercicio de la caridad pastoral hallarán el vínculo de la perfección sacerdotal, que reduzca a unidad su vida y acción (PDV, 23). 


\subsection{La espiritualidad del Hermano}

El presbítero tiene en el presbiterio su primera comunidad de pertenencia. Está llamado a compartir su fe, en primer lugar con sus hermanos en el ministerio. Es la experiencia del cenáculo. Esto salva al sacerdote de la soledad y del activismo, porque tanto uno como el otro lesionan el ejercicio de su ministerio ${ }^{8}$. Al sacerdote se le pide un amor sin límites, especialmente en una relación personal con el presbiterio, unido en y con el obispo. Esta espiritualidad del hermano le lleva a reconocer en todos a iguales y a colaborar en beneficio de todos con una serie de virtudes que deben entenderse como propias del presbítero: fidelidad, coherencia, acogimiento, afabilidad, firmeza doctrinal, desprendimiento, paciencia, gusto por el esfuerzo diario, confianza en la acción de la gracia; todo esto configura la verdadera imagen del sacerdote como buen pastor a ejemplo de Jesucristo.

La orientación pastoral debe ser delineada en sus expresiones concretas por los propios formadores de los seminarios. Los contenidos y las características dependerán de múltiples factores propios de cada lugar y de acuerdo a las circunstancias. Sin embargo el Papa ofrece algunas pistas, entre las que habría que destacar la necesidad de ofrecer un proyecto único y orgánico de vida cristiana y sacerdotal, que comienza con la formación inicial en el Seminario y continúa en la formación permanente (42) y la importancia que reviste la formación humana como base para la formación espiritual, subrayando la capacidad de relacionarse con los demás, y la madurez afectiva. La vida espiritual se debe fundamentar en una experiencia profunda de fe:

Esta experiencia de fe vivida, se transforma en fe comprendida por el estudio, en fe compartida por la relación fraterna y, finalmente, en fe anunciada por la acción pastoral.

El tema de la espiritualidad del sacerdote, abordado por el Papa en su exhortación apostólica, es visto en un dimensión eminentemente relacional. Esto quiere decir que la espiritualidad del sacerdote implica un estilo de vida en relación con Dios en Cristo, y con los hombres a quienes sirve como pastor y testigo o transparencia de Cristo.

Hablar en una dimensión relacional significa básicamente hacer referencia a Cristo sacerdote y buen pastor, o sea, tener como centro a Cristo para todas las actividades en la vida del sacerdote y esto, a su vez, nos indica ya un determinado estilo de vida del Presbítero:

La espiritualidad en el sacerdote la podemos entender a partir de la llamada

8 Dentro de la comunidad eclesial, la caridad pastoral del sacerdote le pide y exige de manera particular y específica una relación con el presbiterio, unido en y con el obispo (PDV, 23). 
universal a la santidad, que consiste en un dinamismo del Espíritu que orienta hacia la perfección de la caridad (9), se trata de la caridad pastoral. Esta expresión, utilizada ya desde el documento de la Presbyterorum Ordinis, se repite como nota característica de la espiritualidad del sacerdote y se entiende como la donación que hace el Buen Pastor de sí mismo y que debe expresarse en la vida de los sacerdotes en virtud de su participación en la misión única de Cristo por el sacramento del orden (PDV, 21).

\subsection{La vida espiritual, una respuesta}

La vida espiritual se presenta como centro vital que unifica y vivifica su ser sacerdote y su ejercer el sacerdocio (45). La importancia de esta vida espiritual, se subraya en todo el documento. Debe entenderse como respuesta consciente y libre que implica a toda la persona en su adhesión a Jesucristo, que llama a su intimidad de vida y a participar en su misión salvifica (42).

La respuesta de la espiritualidad es presentada con una serie de características que configuran el estilo de vida, sobre todo del sacerdote diocesano. Estas características deben ser tomadas en cuenta precisamente para configurar no sólo la identidad del sacerdote, sino también su formación hacia el ministerio sacerdotal. Cada una de estas características de suyo formarían todo un programa de vida espiritual; todas ellas se complementan; todas derivan de la configuración y relación con Cristo y todas, finalmente, se concretan en la caridad pastoral. 